\title{
Analysis for Organochlorine Pesticide Residues in Honey from Kabale District, South-Western Uganda
}

\author{
Benon Ntirushize ${ }^{1}$, John Wasswa ${ }^{2}$, Emmanuel Ntambi ${ }^{1}$, Christopher Adaku ${ }^{1}$ \\ ${ }^{1}$ Department of Chemistry, Mbarara University of Science and Technology, Mbarara, Uganda \\ ${ }^{2}$ Department of Chemistry, Makerere University, Kampala, Uganda \\ Email: *ntirushizebenon@yahoo.com
}

How to cite this paper: Ntirushize, B., Wasswa, J., Ntambi, E. and Adaku, C. (2019) Analysis for Organochlorine Pesticide Residues in Honey from Kabale District, South-Western Uganda. American Journal of Analytical Chemistry, 10, 476-487. https://doi.org/10.4236/ajac.2019.1010034

Received: September 12, 2019

Accepted: October 202019

Published: October 23, 2019

Copyright $\odot 2019$ by author(s) and Scientific Research Publishing Inc. This work is licensed under the Creative Commons Attribution International License (CC BY 4.0).

http://creativecommons.org/licenses/by/4.0/

\begin{abstract}
This study was motivated by the reported accumulation of Organochlorine Pesticides (OCPs) residues in the various environmental matrices within Uganda, resulting from their use in agriculture and health sectors. This raised a concern of the likelihood of the accumulation of the OCPs residues in the honey produced within the country which would affect its purity as well as quality and consequently its competition on the world market. Sixty representative honey samples were collected from selected local beekeepers from four sampling stations in Muko sub-county, Kabale, and extracted for OCPs using a solid-phase procedure followed by a florisil column packed clean-up method and Gas Chromatography-Electron Capture Detector (GC-ECD) analysis. Confirmation of the selected samples was done using an Agilent (6890N, USA) gas chromatograph combined with a mass spectrometer. Recoveries of spiked samples ranged from $71 \%$ to $96 \%$, except for pp-DDE (54\%), with relative standard deviations from $2 \%$ to $14 \%$ in terms of repeatability, and from $4 \%$ to $17 \%$ in terms of reproducibility. Limits of quantification were from 0.003 to $0.1 \mathrm{mg} \cdot \mathrm{kg}^{-1}$. Endosulfan sulfate was the most frequently detected in $38 \%$ of the samples, followed by HexaChloroBenzene (Lindane) in $21 \%$ of the samples. Residues of DDT and their metabolites were detected in $17 \%$ of the samples. Mean concentrations of the pesticide residues detected range from ND (not detected) to $1.53 \mu \mathrm{g} / \mathrm{Kg}$. The acceptable Maximum residual limits (MLRs) are $200-300 \mu \mathrm{g} \cdot \mathrm{kg}^{-1}$ fresh weight for dieldrin, $500 \mu \mathrm{g} \cdot \mathrm{kg}^{-1}$ for DDT and break down products, and $50 \mu \mathrm{g} \cdot \mathrm{kg}^{-1}$ wet weight for Lindane (WHO/FAO 2011). Results indicate that the levels of OCP residues detected in honey from the country's South Western District of Kabale were within the acceptable limits, and hence this honey was safe for human consumption.
\end{abstract}




\section{Keywords}

Persistent Organic Pollutants, Organochlorine Pesticides, Metabolites, Kabale District, Honey

\section{Introduction}

Organochlorine pesticides (OCPs) are persistent organic pollutants (POPs) characterized by high toxicity, persistence, high chemical stability, poor water solubility, low vapour pressures [1] accumulation [2]. OCPs were used from 1940s in large quantities in agriculture and pest control, but were banned in many countries in 1970s because of their persistence in the environment [3]. Despite restrictions and bans on their use in 1970s, some of these chemicals are still being used in Uganda for crop production and vector control [4] because their residues have been found in various environmental matrices within the country. For instance, OCPs were detected in fish and water samples from Lake Victoria, Uganda [5]. DDT and its metabolites were detected in fish from Lake Edward, Uganda [5], OCPs in soils from south-western Uganda [6], OCPs in fresh and pasteurized cow's milk from Kampala markets [7], OCPs in sediments from the Uganda side of Lake Victoria [8], OCPs in skin, flesh and whole carrots (Daucus carota) from markets around Lake Victoria basin, Uganda [4]. Representatives of these pollutants are: DDT and its major metabolites (Figure 1), isomers of DDT, DDD and DDE (Figure 2) etc.

A recent inventory on pesticide use within Uganda [5] has shown a $6 \%$ response use of dieldrin among the commonly used pesticides in the country, suggesting that the pesticide was still being used by farmers to control various pests.

Slow degradation of pesticides in the environment and extensive or inappropriate use by farmers can lead to environmental contamination of water, soil, air, several types of crops and indirectly, humans [9] [10]. Organochlorine pesticides can enter the environment after pesticide applications, disposal of contaminated wastes into landfills, incinerator emissions or runoff, or releases from manufacturing plants that produce these chemicals [11]. OCPs are harmful to<smiles>CCC(C)CCC(Cl)c1ccc(C(CCl)c2ccc(Cl)cc2)cc1</smiles>

Figure 1. DDT and its major metabolites. 

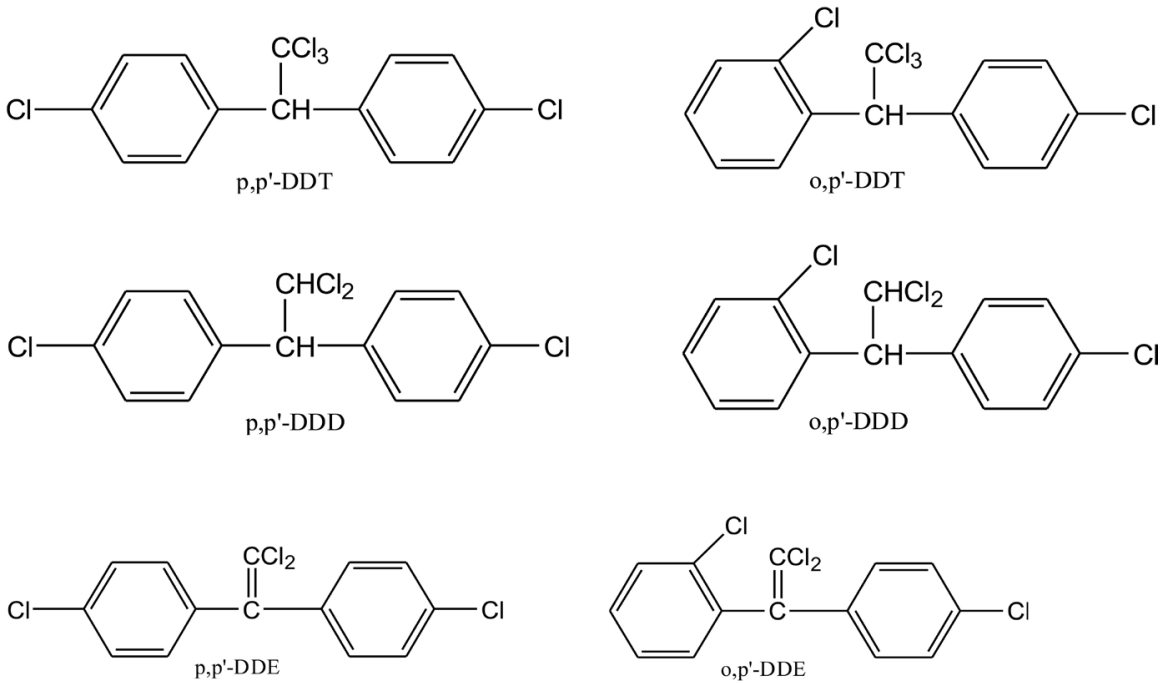

Figure 2. Isomers of DDT, DDD and DDE.

both humans and the environment [12] and do not have target organism. Adverse health effects including reproductive failures, tumour induction, endocrine disruption and cancers can occur once living organisms are exposed to OCPs [13]. For infants whose enzymatic and metabolic systems are not fully active, these chemicals pose a serious risk to their health [14].

Several epidemiological studies suggest that maternal employment to pregnant mothers in agriculture may be a risk factor for birth defects [15] [16] [17].

A multiresidue method able to detect and quantify pesticides in a relatively short period, comprising minimum extraction and clean-up steps is crucial for an efficient monitoring program [18]. Pesticides in honey are usually extracted by treating the sample with an organic solvent [19] [20], or in a solid phase, by the passage through octadecylsilane cartridges [19] [21] after dilution of the honey sample with water.

Kabale district has been particularly chosen as the study region because it has the greatest number of activities involving the use of pesticides such as Irish potatoes cultivation, growth of vegetables such as cabbages and tomatoes, as well as grain crops such as sorghum [22]. Concerns over increased pollution as a result of the above activities have led to efforts being made to address the root causes. No study, however, has been carried out to assess the pesticide residue input to the study area's current state of pollution. Since honey bio-accumulate pesticide residues especially organochlorine, analysis of honey samples can be used to indicate presence of OCP residues.

The present paper reports and assesses the levels of OC pesticide residues in honey from Kabale district, south-western Uganda. The results of this research study will be used to assess the levels of Organochlorine pesticide residues that could accumulate in the environment exposed to OCPs after pesticide application. The findings made are expected to create public awareness through sensitization of all stakeholders about the dangers of POPs of both primary and secondary origin to communities and environment. 


\section{Materials and Methods}

\subsection{Study Area}

The area of study was Rubanda County, located in Kabale district $\left(01^{\circ} 15^{\prime} 00^{\prime \prime}\right.$ South, $29^{\circ} 59^{\prime} 24^{\prime \prime}$ East) [23] in the south-western region of Uganda and is $420 \mathrm{~km}$ from Uganda's capital city, Kampala (Figure 3). Kabale district was chosen because it has a diversity of economic activities such as Irish potato growing, vegetables and fruit cultivation as well as bee keeping by the local communities. All the above mentioned activities are boosted by pesticide application, especially the Organochlorine pesticides.

\subsection{Sample Collection and Preservation}

A total of 60 representative honey samples were collected from selected local beekeepers in Muko sub-county. The samples were obtained from the four sampling stations of Kaara, Ikamiro, Nyarurambi and Kalengere parishes, all neighboring icyuya forest in Kabale district. The samples were left in their original containers and transported to the pesticide laboratory, Chemistry department at Makerere University. They were labeled using permanent markers and then kept in refrigerator maintained at $10^{\circ} \mathrm{C}$ before and during extraction.

\subsection{Extraction of Honey Samples for OCP Residues}

Honey samples were screened prior to extraction, to remove wax, combs, nectar

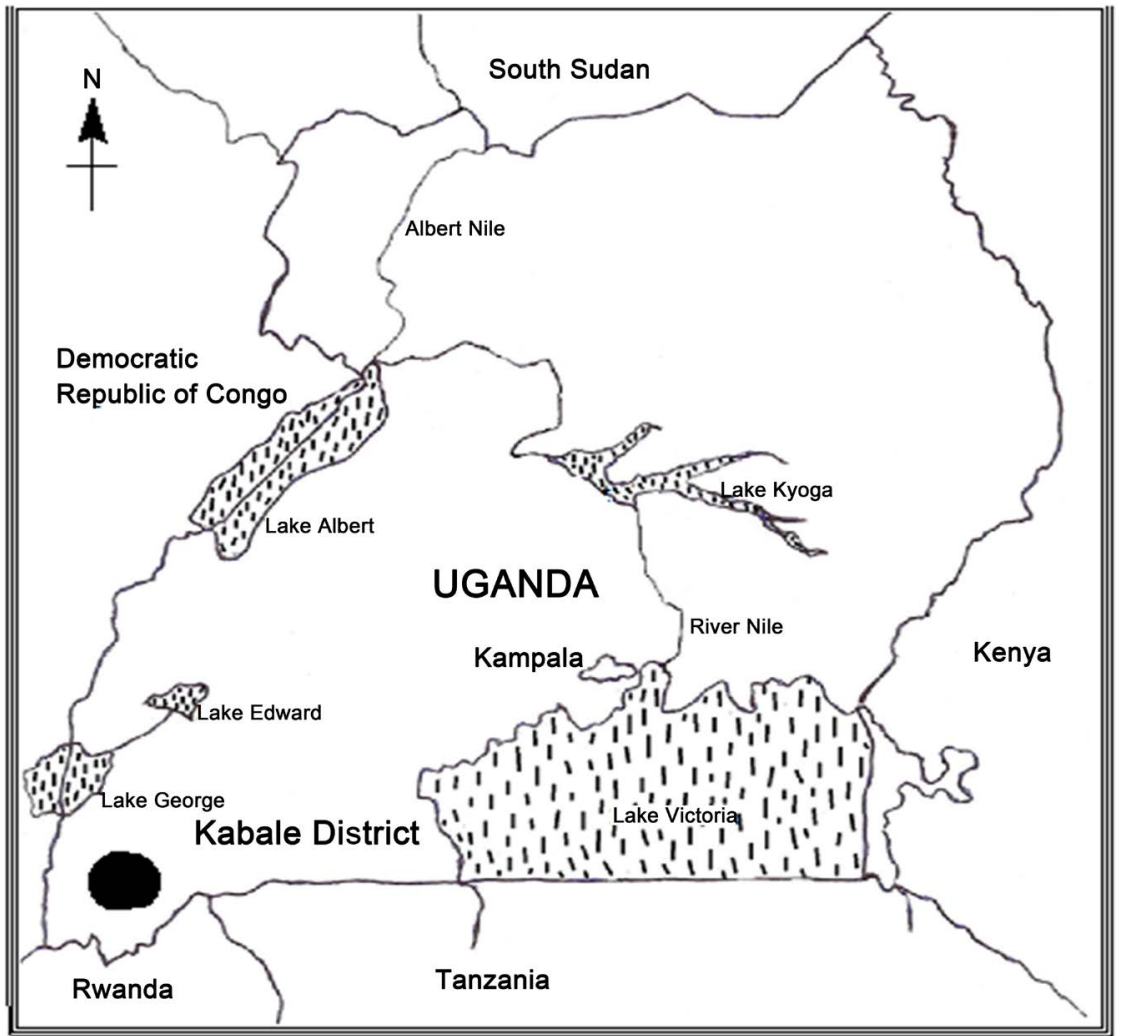

Figure 3. Schematic map of Uganda showing location of study area. 
and other materials. They were extracted for the OCP residues using the solid-liquid dispersion method [24].

The honey sample $(5 \mathrm{~g})$ was dissolved in $10 \mathrm{ml}$ of de-ionized water and extracted with $3 \times 10 \mathrm{ml}$ of $\mathrm{n}$-hexane by magnetic stirring for 15 minutes.

The emulsion formed was broken centrifuging at $4000 \mathrm{rpm}$ for 10 minutes. The organic was filtered by anhydrous sodium sulphate and then concentrated to $1 \mathrm{ml}$. The extract was then cleaned up by florisil technique.

\subsection{Clean up of Honey Samples by Florisil}

The clean-up of the honey extracts by florisil followed procedures as described by [25]. A glass column $(4 \mathrm{~mm}$ id $\times 15 \mathrm{~cm})$ on a retort stand was rinsed with 10 $\mathrm{ml}$ of hexane to remove any impurities, and then plugged with glass wool previously rinsed with $\mathrm{n}$-hexane. The column was then packed with florisil ( $2.0 \mathrm{~g})$ followed by anhydrous sodium sulphate $(1.0 \mathrm{~g})$. The pesticides residues were eluted with $25 \mathrm{ml}$ of $15 \%$ of diethyl ether in $\mathrm{n}$-hexane. The eluate was concentrated using rotary evaporator at $40^{\circ} \mathrm{C}$ and $335 \mathrm{mmHg}$, and the final residue collected was concentrated to dryness under a stream of nitrogen, after which it was transferred quantitatively for the GC-ECD analysis.

\subsection{Gas Chromatographic Analysis}

OCP residues were analysed using a Varian (CP-3800, Palo Alto, CA, USA) gas chromatograph equipped with a ${ }^{63} \mathrm{Ni}$ Electron Capture Detector (ECD) and SPB-1 $0.53 \mathrm{~mm}$ i.d. $\times 60 \mathrm{~m}$ non-polar capillary column. The GC temperature programme was: $90^{\circ} \mathrm{C}$ for $1 \mathrm{~min}$, raised to $180^{\circ} \mathrm{C}$ at a rate of $30^{\circ} \mathrm{C} / \mathrm{min}$, raised to $260^{\circ} \mathrm{C}$ at a rate of $4^{\circ} \mathrm{C} / \mathrm{min}$, and then kept at $260^{\circ} \mathrm{C}$ for 10 minutes for non-polar column. The temperatures of the injector port (model 1079, USA) and ECD were $230^{\circ} \mathrm{C}$ and $300^{\circ} \mathrm{C}$ respectively. The injector volume was $1 \mu \mathrm{l}$, and the carrier gas was hydrogen (99.999\% purity) with electronic flow control at $1.2 \mathrm{ml} / \mathrm{min}$. and nitrogen as the make-up gas at a flow rate of $30 \mathrm{ml} / \mathrm{min}$. A Turbochrom (Perkin-Elmer Corporation, 1989-1995, USA) 4.0 chromatography workstation was used for chromatographic data processing.

The confirmation method used was done using An Agilent 6890 N GC-MS version was used with an HP-5MS fused silica capillary column $30 \mathrm{~m} \times 0.25 \mu \mathrm{m}$ $\times 0.25 \mathrm{~mm}$ i.d. The spectrometer used had a selective detector (Agilent $5975 \mathrm{in}-$ ert XL Duadrupole). The initial temperature was $90^{\circ} \mathrm{C}$ and it was held for 1 minute and then increased at a rate of $30^{\circ} \mathrm{C}$ per minute to $180^{\circ} \mathrm{C}$. The temperature was further increased at a rate of $4^{\circ} \mathrm{C}$ per minute to $280^{\circ} \mathrm{C}$ and held for 15 minutes. The injector temperature was $250^{\circ} \mathrm{C}$ and the detector was maintained at $200^{\circ} \mathrm{C}$.

Helium was used as the carrier gas at $1.0 \mathrm{ml} \cdot \mathrm{min}^{-1}$ flow rate. The GC-MS was operated in a splitless mode with a purge-off of 1 minute and the injection volume was $1 \mu \mathrm{ml}$. The Mass Spectrometer solvent delay time was 3.57 minutes and scanned mass range was $50-550 \mathrm{~m} / \mathrm{z}$. Data acquisition and processing was 
achieved using GC-MSD Chemstation Software (G1701dad.02.0sp1, JAS CWA, USA).

\subsection{Quality Control Procedures}

Recovery tests were done to determine the analytical extraction and clean-up efficiencies of the methods used to extract OCP residues from honey samples. Distilled water samples that were pre-analysed and found to have no detectable residues of the targeted compounds were used as blanks. Recovery tests were done for $o, p^{\prime}$-DDE, gamma Lindane, $p, p^{\prime}$-DDT, and $p, p^{\prime}$-DDE. Each $10 \mathrm{ml}$ of distilled water was spiked with $0.2 \mu \mathrm{g} / \mathrm{ml}$ of each of the following pesticide standards: $o$, $p^{\prime}$-DDE, gamma Lindane, $p, p^{\prime}$-DDT and $p, p^{\prime}$-DDE. Each was subsequently extracted and analysed in the same way as the rest of the honey samples. The cleaned extracts were reconstituted in n-hexane $(1 \mathrm{ml})$ for GC analysis, and the percentage recoveries were calculated. Four sets of experiments for each pesticide were performed. Detection limits, the lowest concentration of the analyte that can be detected above the noise from blank chromatograms, were estimated by considering the lower level of detection (LLD) defined as the concentration that produces a signal sufficiently large that $99 \%$ of the trials with that amount will produce detectable signals. LLDs for individual components were determined according to [26], and are presented in Table 1.

\subsection{Lower Level of Detection (LLD)}

The LLD for $\beta$ - $\mathrm{HCH}$, Dieldrin, Endosulfan sulfate, $\mathrm{HCH}$-gamma, $o, p^{\prime} \mathrm{DDE}$, $p, p^{\prime}$-DDD, $p, p^{\prime}$-DDE, $o, p^{\prime}$-DDT and $p, p^{\prime}$-DDT were $0.007,0.007,0.0063,0.003$, $0.099,0.043,0.059,0.003$ and $0.046 \mu \mathrm{g} \cdot \mathrm{kg}^{-1}$ respectively, as shown in Table 2 below.

\subsection{Identification of OCP Residues}

Identification of OCP residues was done by comparing their retention times with those of standards (Table 3). Relative retention times (RRT) were calculated for all significant peaks which appeared in the sample chromatograms. Samples were run in between mixture of standards containing probable compounds, and their chromatograms compared to those of the standards. The Representative Chromatogram for OCP residues is shown in Figure 4.

The relative retention times were calculated as the ratio of the retention time Table 1. Average percentage recoveries of OCPs $(n=4)$.

\begin{tabular}{lccc}
\hline Pesticide & Amount (average) recovered $(\mu \mathrm{g})$ & Mean percentage recovery & Standard deviation \\
\hline$o, p^{\prime}$-DDE & 0.184 & 96.20 & 0.0013 \\
$\gamma$-Lindane & 0.142 & 71.10 & 0.0017 \\
pp-DDT & 0.149 & 74.30 & 0.0022 \\
p,p'-DDE & 0.108 & 54.20 & 0.0010 \\
\hline
\end{tabular}


Table 2. Lower levels of detection (LLD) $(\mathrm{n}=4)$.

\begin{tabular}{cccc}
\hline OCP & Mean $(\mu \mathrm{g} / \mathrm{kg}) \times 10^{-3}$ & Standard deviation & $\begin{array}{c}\text { LLD }=3.29 \times \text { standard } \\
\text { deviation }(\mu \mathrm{g} / \mathrm{kg})\end{array}$ \\
\hline$\beta$-HCH & 1.23 & 0.002 & 0.007 \\
Dieldrin & 1.85 & 0.002 & 0.007 \\
Endosulfan sulfate & 1.23 & 0.019 & 0.063 \\
$\gamma$-HCH & 1.28 & 0.001 & 0.003 \\
o,p'-DDE & 1.05 & 0.030 & 0.099 \\
p,p'-DDD & 1.96 & 0.013 & 0.043 \\
p,p'-DDE & 1.32 & 0.018 & 0.059 \\
$o, p^{\prime}-\mathrm{DDT}$ & 1.21 & 0.001 & 0.003 \\
p,p'-DDT & 1.86 & 0.014 & 0.046 \\
\hline
\end{tabular}

Table 3. Retention times used to identify OCP residues.

\begin{tabular}{ccccc}
\hline \multirow{2}{*}{ Pesticide } & \multicolumn{2}{c}{$\begin{array}{c}\text { Non-polar column SPB-1 } 60 \mathrm{~m} \times 0.53 \\
\mathrm{~mm} \text { i.d. }\end{array}$} & $\begin{array}{c}\text { Semi-polar column CP-Sil } \\
\mathrm{CB} \mathrm{30} \times 0.25 \mathrm{~mm} \text { i.d. }\end{array}$ \\
\cline { 2 - 5 } & $\mathrm{RT}_{\text {std }}(\mathrm{min})$ & $\mathrm{RT}_{\text {sample }}(\mathrm{min})$ & $\mathrm{RT}_{\text {std }}(\mathrm{min})$ & $\mathrm{RT}_{\text {sample }}(\mathrm{min})$ \\
\hline Endosulfan sulfate & 16.49 & 16.47 & 16.46 & 16.45 \\
$\alpha$-Endosulfan & 13.08 & 13.09 & 10.92 & 10.91 \\
$p, p^{\prime}$-DDE & 13.98 & 13.96 & 13.10 & 13.09 \\
$p, p^{\prime}$-DDD & 18.18 & 18.19 & 15.26 & 15.27 \\
$p, p^{\prime}$-DDT & 19.75 & 19.72 & 19.69 & 19.68 \\
$o, p^{\prime}$-DDT & 18.49 & 18.47 & 18.45 & 18.44 \\
Dieldrin & 13.94 & 13.96 & 12.24 & 12.22 \\
$\alpha$ - $\mathrm{HCH}$ & 7.42 & 7.09 & 6.55 & 6.66 \\
$\beta$ - $\mathrm{HCH}$ & 7.79 & 7.75 & 9.18 & 9.16 \\
$\gamma$-HCH & 7.48 & 7.45 & 7.05 & 7.09 \\
\hline
\end{tabular}

$\mathrm{RT}_{\text {std }}=$ Retention time of the standard, $\mathrm{RT}_{\text {sample }}=$ Retention time of the sample.

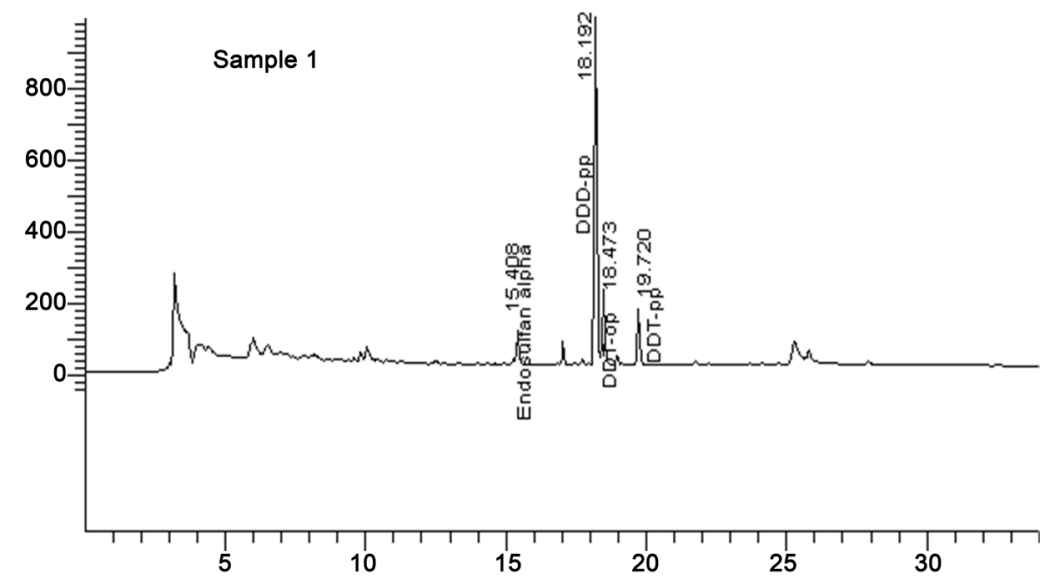

Figure 4. Representative chromatogram for OCP residues. 
of a compound to that of parathion methyl. Confirmation on the GC-MS majorly involved the use retention times of the OCP residues detected from the honey sample extracts as compared to retention times of the standards used. This represented by Figure 5 .

\section{Results and Discussion}

\subsection{Results}

This study documented the first known analysis of Organochlorine pesticide residues in Honey from Kabale district in particular and Uganda in general. The organochlorine pesticide residues detected were dieldrin $\left(1.22 \mu \mathrm{g} \cdot \mathrm{kg}^{-1}\right), \mathrm{p}, \mathrm{p}^{\prime}-\mathrm{DDT}$ $\left(0.23 \mu \mathrm{g} \cdot \mathrm{kg}^{-1}\right), \mathrm{p}, \mathrm{p}^{\prime}$-DDE $\left(0.74 \mu \mathrm{g} \cdot \mathrm{kg}^{-1}\right), \mathrm{p}, \mathrm{p}^{\prime}-\mathrm{DDD}\left(0.82 \mu \mathrm{g} \cdot \mathrm{kg}^{-1}\right)$, endosulfan sulphate $\left(0.67 \mu \mathrm{g} \cdot \mathrm{kg}^{-1}\right)$, alpha endosulfan $\left(0.90 \mu \mathrm{g} \cdot \mathrm{kg}^{-1}\right)$, Heptachlor epoxide $\left(0.16 \mu \mathrm{g} \cdot \mathrm{kg}^{-1}\right)$, beta lindane $\left(1.04 \mu \mathrm{g} \cdot \mathrm{kg}^{-1}\right)$ and $\gamma-\mathrm{HCH}\left(1.53 \mu \mathrm{g} \cdot \mathrm{kg}^{-1}\right)$ with frequencies of detection ranging from $01 \%$ and $38 \%$ (Table 4 ).

\subsection{Discussion of Results}

In this study, the average recovery for $\mathrm{p}, \mathrm{p}$ '-DDE (54.20\%) was found to be lower than for the rest of organochlorine pesticide residues. This may be attributed to its high volatility and lipophilic properties. The concentration of DDT was lower than for its metabolites; DDD and DDE, implying that, there was no recent application of DDT within the study area. A recent inventory on pesticide use within Uganda [5] has shown a 6\% response use of dieldrin among the commonly used pesticides in the country, suggesting that the pesticide was still being used by farmers to control various pests.

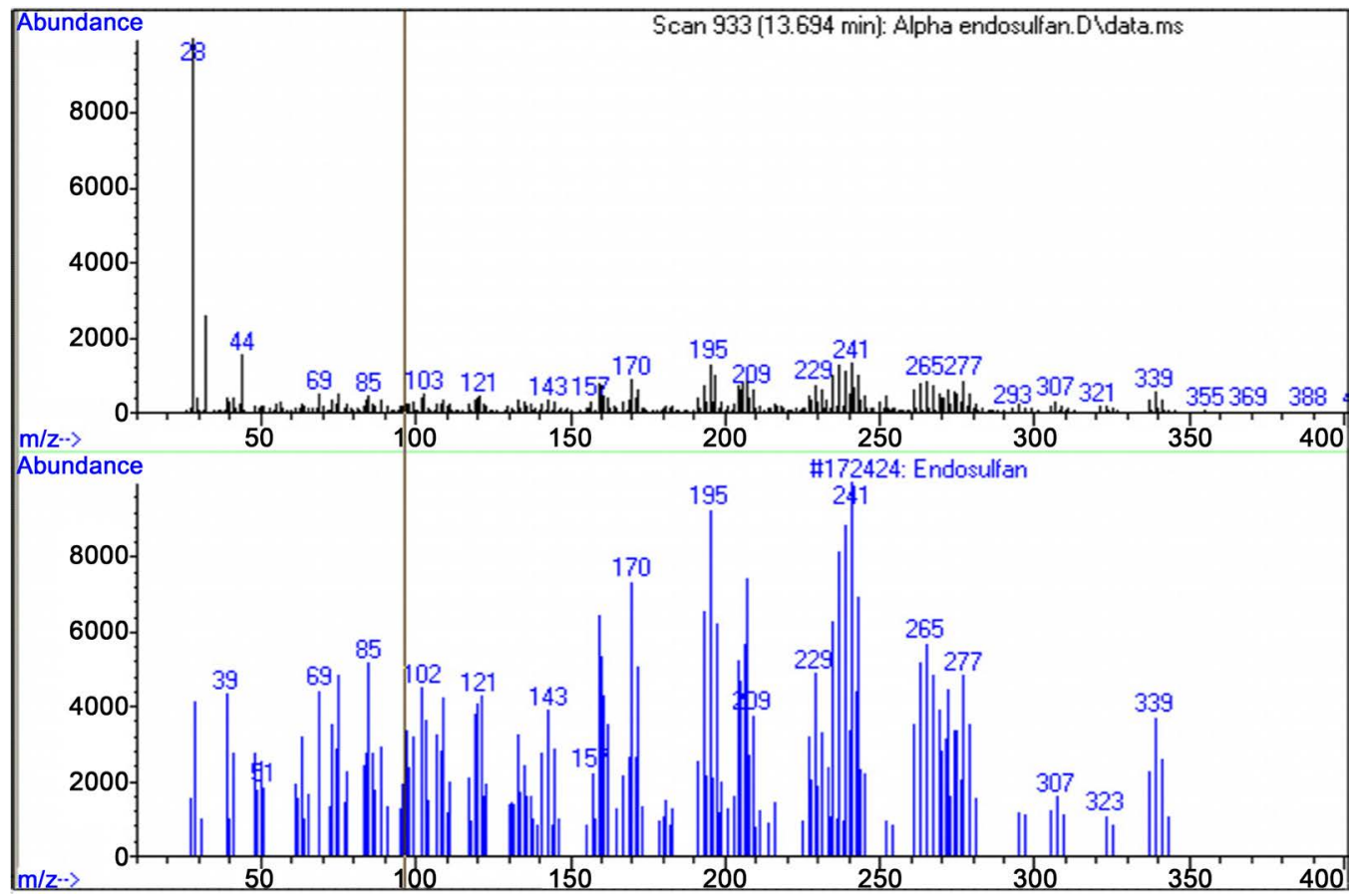

Figure 5. Representative GC-MS spectrum of endosulfan matched against its library spectrum. 
Alpha endosulfan had a higher concentration than that of its metabolite; endosulfan sulphate, implying that there was a recent use of endosulfan within the study area. Results of analysis of honey samples from the district indicated that honey bio-accumulate certain levels of OCPs. The levels of DDT and its metabolites ranged between $0.11-0.74 \mu \mathrm{g} / \mathrm{Kg}$.

Among the metabolites, $\mathrm{p}, \mathrm{p}-\mathrm{DDE}$ recorded the highest frequency of detection (17\%), followed by p,p-DDD (8\%) and p,p-DDT (3\%) and lastly o,p DDT (2\%). Other OCPs were in most cases not detected, with o,p-DDE, $\alpha-\mathrm{HCH}$ and Heptachlor being not detected (ND) at all, with a frequency of $0 \%$. The frequency of detection for each of the OCP residue is shown in Figure 6.

Table 4. Average concentrations of OCP residues in all honey samples collected from four parishes.

\begin{tabular}{cccc}
\hline Component & $\begin{array}{c}\text { Mean concentration } \\
(\mu \mathrm{g} / \mathrm{Kg})\end{array}$ & Standard deviation & Frequency of detection \\
\hline Endosulfan sulfate & 0.67 & 0.013 & 38 \\
$\alpha$-Endosulfan & 0.90 & 0.018 & 09 \\
p,p'-DDE & 0.74 & 0.001 & 17 \\
p,p'-DDD & 0.82 & 0.022 & 08 \\
p,p'-DDT & 0.23 & 0.013 & 03 \\
$o, p^{\prime}-\mathrm{DDT}$ & 0.11 & 0.006 & 02 \\
o,p'-DDE & $\mathrm{ND}$ & - & 00 \\
Dieldrin & 1.22 & 0.013 & 06 \\
$\alpha$-HCH & $\mathrm{ND}$ & - & 00 \\
$\beta$-HCH & 1.04 & 0.015 & 21 \\
$\gamma$-HCH & 1.53 & 0.017 & 02 \\
Heptachlor & $\mathrm{ND}$ & - & 00
\end{tabular}

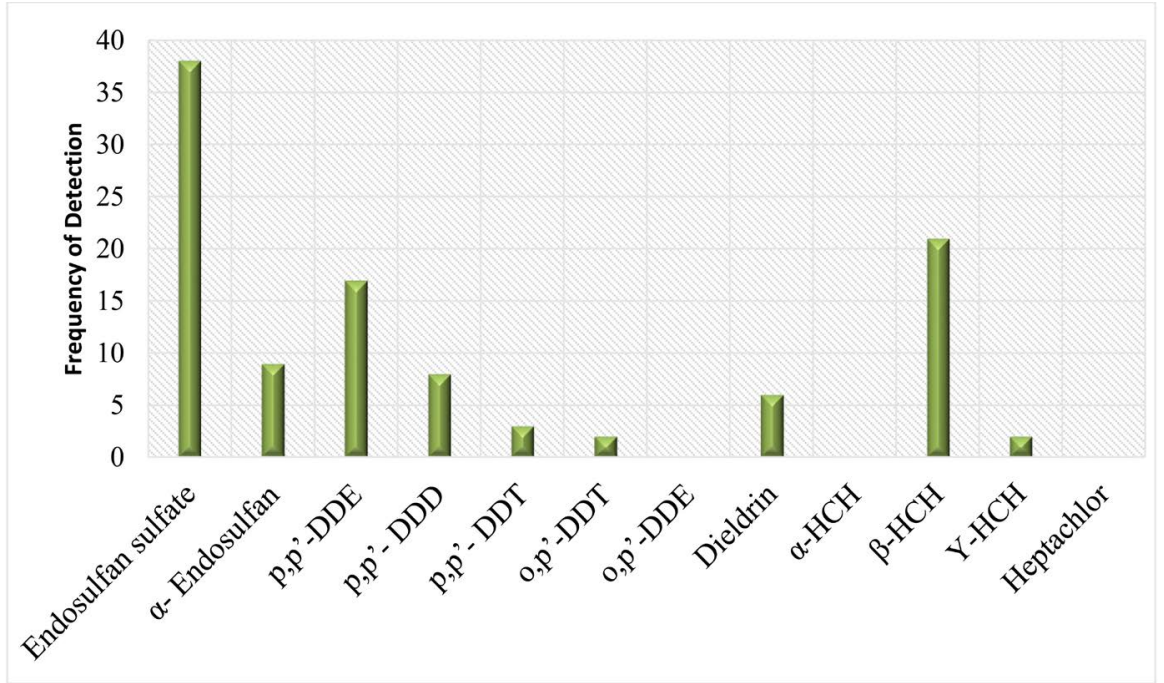

Figure 6. Frequency of detection of OCP residues. 


\section{Conclusion and Recommendations}

\subsection{Conclusion}

The results from this study reveal that the levels of the 12 OC pesticide residues/metabolites detected from the study area were in the range ND - 1.53 $\mu \mathrm{g} / \mathrm{Kg}$. Endosulphan sulphate was the most frequently detected OC residue (38\%), followed by HCB in $21 \%$ of the samples, then residues of DDT and its metabolites in $17 \%$ of the samples. The other OCs identified included dieldrin, DDT isomers (p,p-DDT o,p-DDT) and its metabolites (p,p-DDE, p,p-DDD, o,p-DDD) and lindane isomers (a-HCH, and $\gamma-\mathrm{HCH})$. The results obtained from the present study do not raise much concern regarding the potential health effects of OCPs on residents of Kabale District, who use honey and other bee products. This is because, although residues of the OCPs were detected in some of the honey samples studied, their levels were lower than the WHO/FAO Maximum Residual Limits (MRL). Results indicate that the levels of OCP residues detected in honey from the country's South Western District of Kabale were within the acceptable limits, and hence this honey was safe for human consumption.

\subsection{Recommendations}

Although OCPs have made positive contribution to agriculture and health sectors to control pests and diseases in tropical countries like Uganda, they have been found affecting non-target organisms including Man. This is due to their bio-accumulation tendencies and ubiquitous nature, making their use unsuitable and a great threat to the environment and its biodiversity. There is therefore need for periodic monitoring of such persistent pesticides in order to obtain information on the quality of honey from Kabale district and Uganda in general, even if there seems to be no biological threat from their use.

The government of Uganda and other appropriate agencies should educate farmers on good agricultural practices (GAP) that involve use of pesticides, Such as integrated pest management (IPM); this can significantly reduce pesticide use without reducing yields.

It is also recommended that, a study should be done on honey combs to assess their ability to accumulate pesticide residues in comparison to the levels of the OCP residues reported in this study.

\section{Acknowledgements}

I am thankful to Dr. John Wasswa, Dr. Ntambi Emmanuel and Mr. Adaku Christopher for tirelessly supervising this research work, as well as Kabale University, Kabale, Uganda for partially sponsoring this study.

\section{Conflicts of Interest}

The authors declare no conflicts of interest regarding the publication of this paper. 


\section{References}

[1] Bouwman, H. (2004) South Africa and the Stockholm Convention on Persistent Organic Pollutants. South African Journal of Science, 1000, 323-328.

[2] Lucrezia, C. (2012) Uruguay's Organochlorine Pesticides Regulation in Relation to International Laws.

[3] Coulston, F. (1985) Reconsideration of the Dilemma of DDT for the Establishment of an ADI. Regulatory Toxicology and Pharmacology, 5, 332-383. https://doi.org/10.1016/0273-2300(85)90002-9

[4] Nannyonga, S., Kiremire, B.T., Patrick, O., Nyanzi, S.A., Mohammed, L. and Sserunjogi, W. (2012) Organochlorine Pesticide Residues in Skin, Flesh and Whole Carrots (Daucus carota) from Markets around Lake Victoria Basin, Uganda. International Journal of Environmental Studies, 70, 49-58. https://doi.org/10.1080/00207233.2012.749565

[5] Kasozi, G.W., Kiremire, B.T., Bugenyi, W.B., Kirsch, N.H. and Nkedi-Kizza, P. (2006) Organochlorine Residues in Fish and Water Samples from Lake Victoria, Uganda. Journal of Environmental Quality, 35, 584-589. https://doi.org/10.2134/jeq2005.0222

[6] Ssebugere, P., Wasswa, J., Mbabazi, J., Nyanzi, S.A., Kiremire, B.T. and Marco, J.A.M. (2010) Organochlorine Pesticides in Soils from South-Western Uganda. Chemosphere, 78, 1250-1255. https://doi.org/10.1016/j.chemosphere.2009.12.039

[7] Kampire, E., Kiremire, B.T., Steven, N. and Kishimba, M. (2011) Organochlorine Pesticide in Fresh and Pasteurized Cow's Milk from Kampala Markets. Chemosphere, 84, 923-927. https://doi.org/10.1016/j.chemosphere.2011.06.011

[8] Wasswa, J., Kiremire, B.T., Nkedi-Kizza, P., Mbabazi, J. and Ssebugere, P. (2011) Organochlorine Pesticide Residues in Sediments from the Uganda Side of Lake Victoria. Chemosphere, 82, 130-136. https://doi.org/10.1016/j.chemosphere.2010.09.010

[9] Olkowski, W. (1991) Common Sense Pest Control. Timmons, C., Ed., Taunton Press, Newtown, 63.

[10] Hamilton, D. and Crossley, D. (2004) Pesticide Residues in Food and Drinking Water-Human Exposure and Risks. John Wiley Sons, Hoboken. https://doi.org/10.1002/0470091614

[11] Fernandez, M.A., Sancho, M.T., Gandara, J., Creus, J.M., Huidobro, J.F. and Lozano, J. (2003) Organochlorine Pesticide Residues in Galician (NW Spain) Honey. Apidologie, 26, 33-38. https://doi.org/10.1051/apido:19950105

[12] Hunter, D.J., Hankinson, S.E., Laden, F., Colditz, G.A., Manson, J.E., Willet, W.C., Speizer, F.E. and Wolf, M.S. (1997) Plasma Organochlorine Levels and the Risk of Breast Cancer. The New England Journal of Medicine, 337, 1253-1258. https://doi.org/10.1056/NEJM199710303371801

[13] Makris, S.L. and Rowe, J.N. (1998) Implementation of the Food Quality Protection Act (FQPA) as It Relates to Enhanced Sensitivity of Children. Teratology, 57, 246.

[14] Garry, V.F. (2004) Pesticides and Children. Toxicology and Applied Pharmacology, 198, 152-163. https://doi.org/10.1016/j.taap.2003.11.027

[15] Nurminen, T. (1995) Maternal Pesticide Exposure and Pregnancy Outcome. Journal of Occupational and Environmental Medicine, 37, 935-940. https://doi.org/10.1097/00043764-199508000-00008

[16] Weidner, et al. (1998) Different Axonal Properties of Mechanosensitive and Mechanoinsensitive C-Nociceptors. Society for Neuroscience Abstracts, 24, 383. 
[17] Engel, L.S., O’Meera, E.S. and Schwartz, S.M. (2000) Maternal Occupation in Agriculture and Risk of Defects in Washington State, 1980-1993. Scandinavian Journal of Work, Environment \& Health, 26, 193-198. https://doi.org/10.5271/sjweh.531

[18] Bogdanov, S. (1999) Current Status of Analytical Methods for the Detection of Residues in Bees Products. Apiacta, 38, 190-197.

[19] Tsipi, D., Triantafyllou, M. and Hiskia, A. (1999) Determination of Organochlorine Pesticide Residues in Honey, Applying Solid Phase Extraction with RP-C18 Material. Analyst, 124, 473-475.

[20] Fernández, M., Picó, Y. and Manes, J. (2002) Analytical Methods for Pesticide Residue Determination in Bee Products. Food Protection, 65, 1502-1511. https://doi.org/10.4315/0362-028X-65.9.1502

[21] Blasco, C., Fernandez, M., Pena, A., Lino, C., Silveira, M.I. and Font, G. (2003) Assessment of Pesticide Residues in Honey Samples from Portugal and Spain. Journal of Agriculture and Food Chemistry, 51, 8132-8138. https://doi.org/10.1021/jf034870m

[22] National Environment Management Authority Uganda (NEMA) (2000) Inventories for DDT under the Project for the Enabling Activities for the Stockholm Convention on Persistent Organic Pollutants (POPs): National Implementation Plans for Uganda. 42-44.

[23] Wikipedia (2011) Kabale District. http://en.wikipedia.org/wiki/KabaleDistrict

[24] Åkerblom, M. (1995) Environmental Monitoring of Pesticide Residues: Guideline for SADAC Region, SADC/ELMS, Monitoring Techniques Series, Sweden.

[25] Kegley, S.E. and Laura, J.W. (1998) Pesticides in Fruits and Vegetables. University Science Books, University of California, Oakland, 87.

[26] Eaton, A.D., Clesceri, L.S. and Greenberg, A.E. (1995) Standard Methods for the Examination of Water and Wastewater. 19th Edition, American Public Health Association, Washington DC. 